Rakenteiden Mekaniikka

Vol. 50, Nro 3, 2017, s. 345-348

https://rakenteidenmekaniikka.journal.fi/index

https://doi.org/10.23998/rm.65172

(CKirjoittaja(t) 2017.

Vapaasti saatavilla CC BY-SA 4.0 lisensioitu.

\title{
X-liitoksen vinoutumisnurjahdus
}

Timo Björk ${ }^{1}$, Niko Tuominen ja Antti Ahola

Tiivistelmä. Tutkimuksessa tuodaan esiin uusi vaihtoehto täysleveän X-liitoksen vaurioitumiselle. Poikkileikkauksiltaan kotelomaisista sauvoista koostuva liitos voi menettää kantokykynsä myös vinoutumisnurjahtamalla, jolloin poikittaispalkin poikkileikkaus vinoutuu. Analyyttinen malli perustuu virtuaalisen siirtymän synnyttämän muodonmuutostilan energiatasapainoon.

Avainsanat: X-liitos, stabiilius, kantokyky, vinoutumisnurjahdus

Vastaanotettu 9.7.2017. Hyväksytty 19.8.2017. Julkaistu verkossa 21.8.2017.

\section{Johdanto}

Puristuskuormitetun X-liitoksen kapasiteetti perustuu Eurocode 3 [1] mukaisesti joko liitoksen plastisoitumisesta tai uuman lommahduksesta määräytyvään kuormituksen rajatilaan (Kuva 1a-b). X-liitos voi menettää kapasiteettinsa kuitenkin myös Kuvan 1c mukaisesti vinoutumisnurjahduksella.

(a)

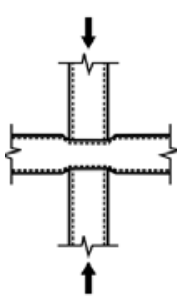

(b)

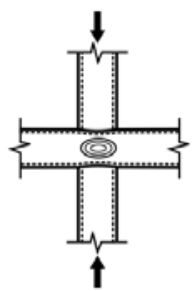

(c)

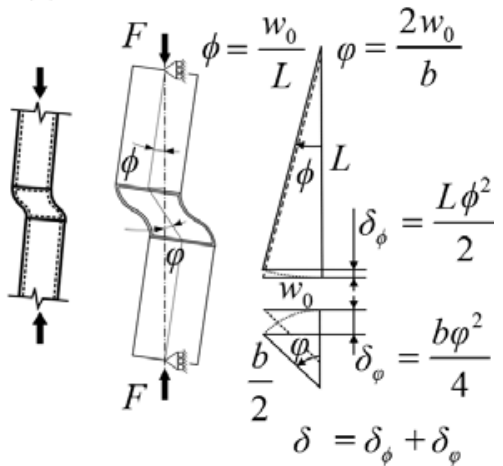

Kuva 1. Puristuskuormitetun täysleveän X-liitoksen vauriomuotoja: poikittaispalkin a) plastisoituminen, b) uuman lommahdus ja c) vinoutumisnurjahdus sekä d) vinoutumismekanismi reunaehtoineen.

${ }^{1}$ Vastuullinen kirjoittaja. timo.bjork@lut.fi 


\section{Liitoksen vinoutumisnurjahdus}

Vinoutumisnurjahduskestävyys määritetään Kuvan 1d mukaiselle liitokselle, jossa aksiaalisesti puristuskuormitetut haarat ovat päistään nivelellisesti tuettuja (vastaten pystysuunnassa jatkuvan rakenteen antimetristä tuentaa). Poikittaispalkki on vapaa kiertymään pituusakselinsa ympäri vastaten siten sivusuunnissa jatkuvaa rakennetta. Mitoituksessa käytetään seinämien keskilinjoja, eli $b=b_{0}-t$. Voiman $F$ tekemä työ on

$V=-2 F \delta=-2 F\left[L(1-\cos \varphi)+\frac{b}{2}(1-\cos \phi)\right] \approx-2 F\left[L \frac{\varphi^{2}}{2}+\frac{b}{2} \frac{\phi^{2}}{2}\right]=-F\left[\frac{1}{L}+\frac{2}{b}\right] w_{0}^{2}$

Haaraosia voidaan pitää sekä aksiaalisesti että taivutusjäykkyydeltään ideaalisen jäykkänä sauvana. Näin ollen haaran pään siirtymä kuorman suunnassa on $\delta$ ja muodostuu haaran jäykän kappaleen siirtymästä ja poikittaispalkin kimmoisesta siirtymästä. Lausekkeessa (1) $w_{0}$ on asymmetrinen sivuttaissiirtymä poikittaispalkissa liitoksen kohdalla ja muut merkinnät ilmenevät Kuvasta 2.

Deformoituneessa tilassa olevaa liitosta kuormittaa voiman $F$ lisäksi Kuvan 2 mukaisesti horisontaalinen voimapari $F_{h}$, joka voidaan jakaa edelleen puhtaaseen Bredtin teorian mukaiseen voimavuohon ja vinouttavaan voimasysteemiin. Koska poikittaispalkkia ei tässä tapauksessa ole tuettu liitosalueen ulkopuolelta, siinä ei voi esiintyä vääntökuormitusta vaan se on tasapainossa haaran leikkausvoimien ja taivutusmomentin kanssa, joka aiemman jäykkyysoletuksen mukaan ei aiheuta taipumaa haaraosissa.

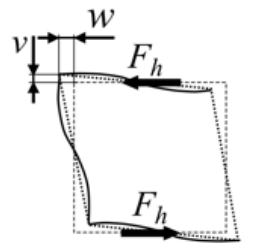

a.

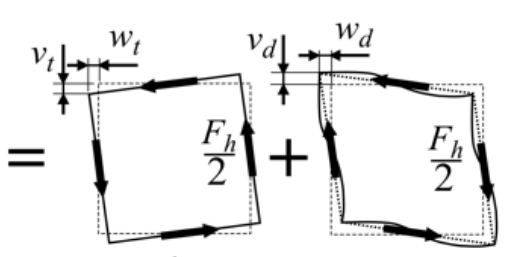

b.

c.

$$
\begin{aligned}
& v=v_{d}-v_{t}=\frac{b}{2 L} w \rightarrow v_{t}=w_{t}=v_{d}-\frac{b}{2 L} w=w_{d}-\frac{b}{2 L} w \\
& w=w_{t}+w_{d}=w_{d}-\frac{b}{2 L} w+w_{d} \\
& w_{d}=v_{d}=\frac{2 L+b}{4 L} w \quad w_{t}=v_{t}=\frac{2 L-b}{4 L} w
\end{aligned}
$$

Kuva 2. Vinoutuneessa poikkileikkauksessa a) vaikuttavat voimat ja esiintyvät siirtymät, jotka muodostuvat b) Bredtin teorian mukaisista osuuksista ja c) vinoutumiskomponenteista.

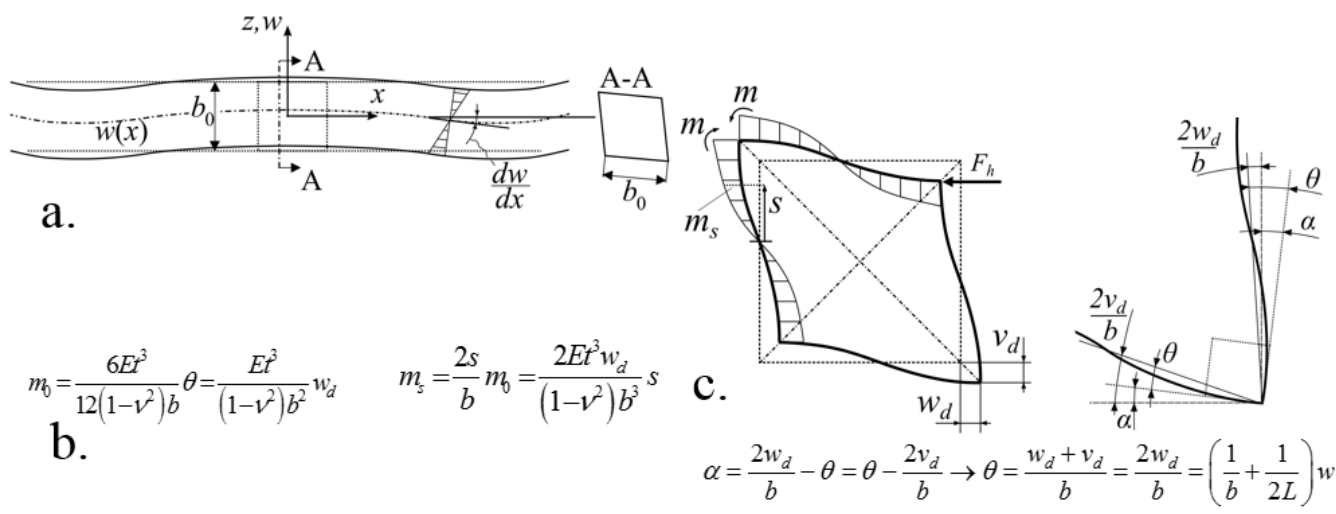

Kuva 3. a) Nivelnurkkaiseksi idealisoidun poikkileikkauksen vinoutuminen, b) taivuttavien momenttien lausekkeet ja c) kehämuodonmuutokset nurkissa. 
Riittävän pitkän poikittaispalkin lineaaris-elastinen vinoutuminen sitoo energiaa seuraavasti:

$U_{d}=\frac{1}{2}\left[8 \int_{0}^{\infty} \frac{E t b^{3}}{12}\left(\frac{d^{2} w_{d}}{d x^{2}}\right)^{2} d x\right]+16 \int_{0}^{\infty}\left[\frac{12\left(1-v^{2}\right)}{E t^{3}} \int_{0}^{\frac{b}{2}} \frac{m_{s}^{2}}{2} d s\right] d x$

missä $E$ on kimmomoduuli, $v$ on Poissonin vakio. Lausekkeen ensimmäinen termi kuvaa poikkileikkauksen vinoutumisessa tapahtuvaan laippojen taipumiseen (tasoissaan) ja toinen termi seinämän taivutusmomentin $m$ sitouttamaan energiaan, jossa otetaan nyt huomioon nurkkien jäykkyys (katso Kuva 3). Momentin sitouttama energia on siten

$\int_{0}^{\frac{b}{2}} \frac{m_{s}^{2}}{2} d s=\int_{0}^{\frac{b}{2}} \frac{E^{2} t^{6} w_{d}^{2}}{\left(1-v^{2}\right)^{2} b^{6}} s^{2} d s=\frac{E^{2} t^{6}}{24\left(1-v^{2}\right)^{2} b^{3}} w_{d}^{2}$

$\mathrm{X}$-liitoksen vinoutumisnurjahdukseen liittyvä kokonaisenergia $\Pi$ on

$$
\Pi=V+U_{d}+U_{t}=-F\left[\frac{1}{L}+\frac{2}{b}\right] w_{0}^{2}+\frac{E t b^{3}}{3} \int_{0}^{\infty}\left(\frac{d^{2} w_{d}}{d x^{2}}\right)^{2} d x+\int_{0}^{\infty} \frac{8 E t^{3}}{\left(1-v^{2}\right) b^{3}} w_{d}^{2} d x
$$

Siirtyneen tilanteen tasapaino syntyy, kun ulkoisen työ on tasapainossa systeemin kimmoenergian kanssa. Vinoutumisnurjahdusta voidaan käsitellä kimmoisella alustalla olevan palkin (BEF)-analogialla ottamalla huomioon vain suppeneva ratkaisuosuus [2], Kun poikittaispalkki oletetaan riittävän pitkäksi, kuomasta $F_{h} / 2$ aiheutuva siirtymä on muotoa

$$
w_{d}=\frac{F_{h} \beta}{4 k} e^{-\beta x}(\sin \beta x+\cos \beta x)
$$

Kimmoisan alustan vakio $k$ ja alustakarakteristika $ß$ [3] saadaan yhtälöistä (8) ja (11)

$$
\begin{array}{r}
m_{0}=\frac{F_{h}}{4} \frac{b}{2}=\frac{E t^{3}}{\left(1-v^{2}\right) b^{2}} w_{d} \\
\frac{F_{h}}{2}=\frac{4 E t^{3}}{\left(1-v^{2}\right) b^{3}} w_{d}=k w_{d} \\
k=\frac{4 E t^{3}}{\left(1-v^{2}\right) b^{3}} \\
\beta=\sqrt[4]{\frac{k}{4 E \frac{b^{3} t}{12}}}=\sqrt[4]{\frac{t^{2}}{\left(1-v^{2}\right) b^{6}}} \\
w_{0}=\frac{4 L}{2 L+b} w_{d, 0}=\frac{L}{2 L+b} \frac{F_{h} \beta}{k}
\end{array}
$$

Haaran kriittiseksi aksiaalikuormaksi saadaan 


$$
F_{c r}=\left(2+\frac{b}{L}\right) b E t\left[\frac{b^{3} \beta^{4}}{12} \int_{0}^{\infty} e^{-2 \beta x}(1-\sin 2 \beta x) d x+\frac{t^{2}}{2\left(1-v^{2}\right) b^{3}} \int_{0}^{\infty} e^{-2 \beta x}(1+\sin 2 \beta x) d x\right]
$$

Integrointi voidaan toteuttaa suljetussa muodossa [4] ja ratkaisuksi saadaan

$$
F_{c r}=\left(2+\frac{b}{L}\right) b E t\left[\frac{b^{3} \beta^{3}}{48}+\frac{3 t^{2}}{8\left(1-v^{2}\right) \beta b^{3}}\right]
$$

Ottamalla huomioon liitospituus $h$ (Kuva 4) X-liitoksen vinoutumisnurjahdukselle ideaalis-elastiseksi kriittiseksi kuormaksi saadaan:

$$
F_{c r}=\left(2+\frac{b}{L}\right) b E t\left[\frac{b^{3} \beta^{3}}{48}(1+2 \beta h)+\frac{t^{2}}{8\left(1-v^{2}\right) \beta b^{3}}(3+2 \beta h)\right]
$$

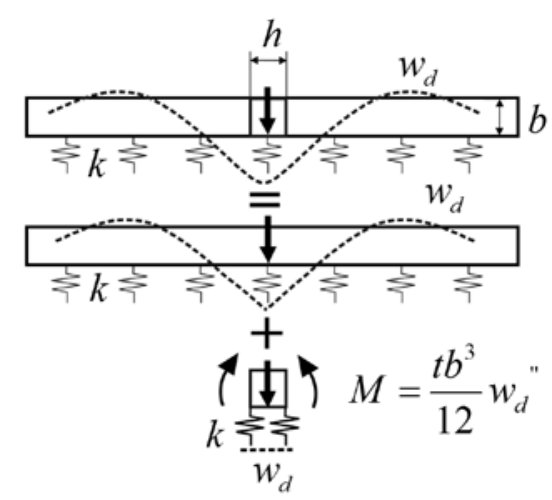

Kuva 4. Yksinkertaistettu malli liitosalueen vaikutuksen huomioonottamiseksi.

\section{Viitteet}

[1] SFS-EN 1993-1-8. Eurocode 3: Teräsrakenteiden suunnittelu. Osa 1-8: Liitosten suunnittelu.

[2] S. Timoshenko. Strength of materials. Part II. Advanced theory and problems. D. Van Nostrand Company, 3. painos, New York, 1958

[3] R.N. Wright, S.R. Abdel-Saman \& A.R. Robinson. BEF analogy for analysis of box girders. Journal of the Structural Division, 94(7): 1719-1744, 1968

[4] W.H. Beyer \& S. Selby. Standard mathematical tables. CRC Press, 24. painos, Ohio, 1976

Timo Björk, Niko Tuominen, Antti Ahola

Lappeenrannan teknillinen yliopisto

Skinnarilankatu 34, PL20, 53851, Lappeenranta

s-posti: timo.bjork@lut.fi,niko.tuominen@lut.fi, antti.ahola@lut.fi 